\title{
Research on the Influence of Contemporary Social Thoughts on College
}

\section{Students' Psychology}

\author{
qiuwei Jiang ${ }^{1, a}$ \\ ${ }^{1}$ Wuhan university of textile, code 430073 \\ a email
}

keywords: Social trend of thought, College Students', Psychology

\begin{abstract}
The globalization of the world economy has become an irresistible trend in nowadays and affect the formation of the multi polarization pattern in the world. With the policy of reform and open China, the export-oriented economy has developed rapidly and along with the input of a variety of western culture, the colorful social trends of thought which led to the collision between Chinese and Western cultures. As the backbone of the young college students, shoulder a historical mission of not to live up to, is the backbone of the country's prosperity, so the mental health of college students must be paid attention to. The college students should use a comprehensive view to "discard the dross, select the essence" in face of a variety of different cultures which to absorb and draw lessons from advanced western culture. They should adhere the characteristics of local cultural , abandon the wrong view of "obsequious to foreign”, to establish a correct concept of value and deal with the change and influence of social thoughts correctly at the same time. The college students should think deeply about the effect of today's social thought on them. This will contribute to achieving the Confucian Humanistic thought of "harmony but not Sameness", improving cultural accomplishment of college students' and it will help to create a good environment for the development of College Students' mental health.
\end{abstract}

\section{Introduction}

The social trend of thought is a kind of social ideology which is reflected differences in each historical period. So the social ideological trend is the theory of social ideology in a certain period of time under the guidance, reflecting the state of mind, the direction of emotional needs and psychological demands at all levels of society. College students are representatives of the legitimate youth, in the key period of forming "World outlook, Outlook on life, values" , influenced by social trends of thought is also great. College students will change due to the social trend of thought, can not set their own outlook on life, world outlook and values correctly especially in the confused period which is leading to distorted values, poor psychological quality and escaped when facing pressure of life or learning, unable to get up after a fall, etc. The response of college students to the social trend of thought, make measures to correct the mistakes timely, promote it's advantages that can "carefully selected" and "survival of the fittest". We should keep positive culture, eliminate inferior and backward culture, promote students to establish correct "World outlook, Outlook on life, values" and promote the development of their mental health.

\section{The Special Features of Contemporary Social Thoughts}

The material determines consciousness, the first is the material, the secondary is consciousness, consciousness is the reflection of the objective world. Consciousness depends on the existence of 
society, so the social trend of thought is a social consciousness essentially, which also depends on the existence of the society, and will give a different performance characteristics of the social ideological trend. The characteristics of the social trends of thought are mainly as four special characteristics under the background of modern times.

Complexity and diversity. The thoughts of all countries in the world have changed greatly, showing a situation that the violent collision and integration with the bi-polar pattern breaks down. The ideology and even rise directly to the value of the concept of the opposition between the state. Along with the increasingly fierce ideological confrontation, all kinds of doctrine has the characteristics of typical western culture with a large number have struck and with strong freedom and democracy. After the third Session of the 18th CPC Central Committee, implementation of the reform and opening policy in our country which is in going out at the same time, also need to lead in. Therefore, the collision is inevitable between Chinese and Western culture, it is facing a variety of cultural and social interaction, so as to set off a social trend of thought with complex and diverse characteristics. It's main performance in the perspective of multi angle research, but also by the impact of research theory and in the content of reaserch, the emphasis is not the same. In general, it has led to the diversity of social trend of thought. Of course, the social trend of thought will be influenced by the nature of the state and the mainstream of social consciousness.

In the thirty years after the founding the people's Republic of China, our country into the big change in the social and economic transformation, this stage was a quite active period of a social trend of thought. Some authorities will divide six in this stage of the social trend of thought , they are Liberal trend of thought, the new authority, the new left, the new nationalism, cultural conservatism and the trend of Democratic Socialism. The six with different values. Because of the active market economy under the reform and opening up, the diversification of interests and society, which are produced in different ideas and in accordance with the interests of the class. Strictly speaking, there is no good or bad points which is also the complexity of the social trend of thought,not only produce different sources, but also affected by a variety of factors and there's no no unified judgment standard. Of course, the diversity and complexity of the social trend of thought is the significant feature of opening, active in the ideology of social mainstream, seeking common ground and reserve differences.

Critical reflectiveness. Contemporary western social thoughts are rooted in the social economy of contemporary western society, which mainly embodies the contradictions and conflicts in the development of western social economy and politics. Of course, in the process of economic globalization, all kinds of culture also interpenetrate to each other to varying degrees. Therefore, the critique and reflection of the modern western thoughts also influence the social trends of thoughts in other countries. The two main themes of the international community are peace and development, and the freedom of democracy is always a hot topic. Thus, many countries has set off a criticism and reflection in the international community, not only to criticizm to a single social trend of thought, but also to reflection on the traditional thinking and there are many schools again, like the voluntarism, existentialism, new utilitarianism, postmodernism and so on.

Visual reality. The social trend of thought is a reflection of social economy, politics and culture to a certain extent in a certain period of time and also in line with the interests of most people in the society at that time. Therefore, it can be used as an understanding of the social conditions in a particular period, which has a direct reality. There are four tendencies in the contemporary western social thoughts, the irrational tendencies, relativism, humanism tendency and focus on global issues, concerned about the future development of mankind. The irrational tendency is mainly against the absolute rationalism, advocates freedom, fully conforms to the modern people's pursuit of "human 
nature”, and is also the embodiment of democracy in society and politics. For example, the system of people's Congress is to attach importance to people's will. Relativism is mainly for absolute science. In the rapid development of modern social science and technology, a considerable part of the theory that has been considered as absolute truth, and then gradually affect the various fields. The humanistic tendency is mainly due to the generalize, emergence and rapid development of the industrialized society. People are faced problems with the emergence of the industrialization and survival , such as the issues of community hot environmental. The final trend of human development is also regarded as the mainstream at the present and in the theme of peace and development, the social development and human development are highlighted.

Global. The root of globalization is that developement rapidly of modern social economy and the fast hopping of science and technology. The earth began to change into a village when the Internet and all three types of traffic of air, land and sea appeared. Cultures also in which collide with each other, learn from each other, mutual improvement, to dross, essence, which is the mandatory policy among countries in the face of cultural agitation. Similarly, the cultural counteractive at the social economy, politics, and therefore, the culture is also turn to globalization, the social trend of thought under the influence of different cultures is also common, or that is the international.

\section{The main influence of contemporary social thoughts on College Students' Psychology}

Improving the ability of students' to resist the complex thoughts of the society. The culture of the new era, to convey the social atmosphere of the real time, and the university students are the main body to accept these new things and to become a leader in contact with the social trend of thought. But in the face of the things never contact they still go astray and easy to be seduced by, so the existence of risk, also need mental health education on College Students', to maintain their ability to sufficient judgment, dealing with impact of social trend of thought.

To cultivate the ability of college students to look at the problem from munti angles. College students'only the use of a comprehensive view of the problem, which can fully respect for all kinds of culture in society, it can judge the merits, preferred, communication and row inferior, abandoned by the practical action, personal experience, sum up experience, observation of the spiritual needs of every corner of the society, cultural vacancy, let the values set carries positive factors of the social trend of thought.

It is helpful for college students to deepen the cultivation of emotional psychology and the desire for good faith.University Students in some people often self-centered, too much self, most care about their own interests, lack of rational thinking, foster personal emotions, resulting in depression, solitary psychology. When the social trend of thought with a new breath, so that the life of college students more than a point of fresh, less old, will gradually inspire their willing to open their hearts, face the desire with sincerely.

\section{The negative influence of contemporary social thoughts on College Students}

The contemporary social ideological trend has caused the loss of the sense of responsibility of some young college students. Everyone begins from the moment of birth, shoulder was given the responsibility, but responsibility seems to be just a kind of invisible pressure, dispensable, originally the sinfinite power should be given to people, but neglected again and again. In contemporary society, responsibility is often used as an excuse cause many people lack a sense of responsibility, especially in the face of an emergency, choose to escape responsibility and shirk. For students, 
personality development of the space is free, broad and often appear extreme egoist, indifference and other issues, causing sense of responsibility is not high in some students', the phenomenon of weak sense of unity.

The contemporary social ideological trend leads to the ideal loss of some young college students. The environment of university is full of opportunities and risks, if students are lost in the confusion, mental and the ideal sail beacon easily, wasted in no hopes of time and fall into the world of darkness at last. Most of the college students not according to the actual situation of their own, but most of the members in the nested social pursuit of values, barely to establish their own ideal but does not conform to their own conditions, resulted in the ideal process of realization with many difficulties and coupled with the lack of active thinking and overcome lack of strength, they are bound to impose their yoke at last, unable to extricate themselves. The ideal practical ability is greatly reduced, and the positive impact on the college students will be greatly weakened.

Contemporary social trend of thought reflects more secular in the part of the young college students. University is a small community, contact diverse with the crowd, the environment is complex. Under the influence of surrounding environment, mammonism and comparisons psychological phenomenon in college students life breeding slowly. And in values set, the physical and mental health of the growth process caused by strong hindering factors. Students should follow the excellent moral character, political literacy of the generations inherited which will be covered by a layer of yarn of splendor, become faint if show, someone may choose to forget, but the choice of reality to follow, simply pursuit of pleasure, comfort yourself, do not use comprehensive vision to look at a problem, but with the secular vision, follow one's inclinations, pay attention to their own of mental satisfaction and material.

Contemporary social thoughts strengthen the non rational awareness of new of some college students. Cultural ideological trend emerged many kinds of culture of different splendor and the emergence of new trends tend to attract youth's eyes, and with the help of this large group, expand the influence of the velocity of propagation. But the pattern of diversification will lead to the wrong type of extremism "new in order to be different" in inferior culture. The concept of excessive consumption "unconventional", complete liberation their ideological nature, lack of rational thinking, social environment of chaos caused by Jian Panxia "network of decay", will cause a series of social problems. Students will be immersed in a moment of pleasure everywhere, "novelty",show their special abnormally, thus losing real life goal and difficult to realize value.

\section{Coping strategies of contemporary social trends of thought on College Students' psychological influence}

To guide college students to establish a scientific world outlook and outlook on life. Aiming at the problem of psychological health education of college students, the colleges and universities should strengthen their efforts of mental health curriculum implementation, guide students to establish a correct concept of culture actively with the ideas of materialist dialectics, from set out actually, follow the objective law, disseminate positive thoughts and culture, promote conducive to good social atmosphere for the formation of the social trend of thought. At the same time, setting up consciousness of self evaluation, objective analysis of their own advantages and disadvantages, do "avoid weaknesses, learn the social trends of thought in the nutrient, enrich my own ideas, further to put into practice, provide strong theoretical support.

Strengthen the research of Humanities and Social Sciences. The study of the humanities and Social Sciences follows the development of the times which is in urgent need of the help of the advanced cultural thoughts. The research point is, on the one hand is updating theory, and better 
service in education of college course. On the other hand, view of the value of the humanities and Social Sciences and college students has close contact with establishment and cultivation the psychological qualities, we need more advanced knowledge of the correct concept of new to the College students, which is positive guidance and impact.

Establishment the system of perfect psychological education. The establishment of mechanism in mental health education will play an important role in the psychological health education of college students. The establishment mechanism of psychological health education is a prerequisite of the college students to form the mental health and psychological quality. It's an important basis for students to deal with the social reality of facing today's fierce competition for learning and life pressure is self-evident. Colleges and universities should establishment the mechanism of humanized psychological health education , make the students to choose suitable way for their own decompression and give the development of their personality, whether it is listening to music, sports, reading,or because of too much pressure to consult a psychiatrist and so on. They should give their own relaxed decompression environment. In addition, when students accept new things, should be considered of their endurance, attitude, ability in advance. For the more prominent of the emotional problems in university campus, the school should open courses related to the emotion, let the students face the emotional setback, correctly deal with emotional problems, out of the haze with a more rational view to solve and analysis to help themsleves.

\section{Conclusion}

Social thoughts are influenced by various factors in the end, therefore, there are three characteristics of the social ideological trend, complexity and diversity, critical reflective and direct reality. As a reflection of certain social conditions in a certain historical period, the social trends of thought reflected not only a school or a kind of doctrine, but the reaction of the whole society under some conditions. Therefore, college students must be realized that there is no good or bad in the social trend of thought. As contemporary college students, we should not only see this, and should be rational treatment. Our country is in the key period of social transition at present, faced with the transformation of all aspects. The college students must stand firm in our position, need to stay awake in the multi surge for to build a harmonious society by themslves.

\section{Acknowledgements:}

The thigh on the influence of contemporary social thoughts on College Students' Psychology for a fund project of Wuhan Textile University in 2014

\section{Reference}

[1] Q.Y. Zhang. The characteristic analysis of the influence of nationalism on College Students' Party building and ideological education in [J]. school (19) (2011)

[2] B.Q. Wang. A thorough understanding of the basic connotation of the social trend of thought [J]. theoretical front in Colleges and universities (11) (2010)

[3] S.H. Yu. The influence of contemporary social thoughts on College Students' study on [J]. characteristics and Countermeasures of Ideological and theoretical education (10):.2010

[4] B.S. Li. The impact of Social Thought on the ideological and political education of college students in.2010 (04): [J].

[5] B.Q. Wang. On the main factors influencing the development of the social ideological trend [J]. school party building and ideological education.2010 (17) 
[6] Q. Zhang. Research on the influence of contemporary social thoughts on College Students' values and guidance [D]. Shaanxi Normal University 2014

[7] Y.N. Cao. The influence of contemporary social thoughts on college students and the Countermeasures [D]. Qiqihar University 2014

[8] X.D. Wei. The influence of contemporary social thoughts on College Students' thought and Countermeasures [D]. Guizhou Normal University.2014

[9] S.S. Zu. An analysis of contemporary Chinese social trends of thought [D]. Qiqihar University 2013

[10] S. Zhang. Study on the influence of social ideological trend on College Students' Ideological and political education [D]. Changchun University of Science and Technology 2011

[11] Y.Tian. The impact of social ideological trend on College Students' Ideological and behavior and the countermeasures to explore the [J]. labor security world.2015 (S2)

[12] Z.G. Meng. Analysis of the connotation, characteristics and research significance of the social trend of thought:.2014 (28) [J]. 